\title{
Grid Frequency Support by Single-Phase Electric Vehicles: Fast Primary Control Enhanced by a Stabilizer Algorithm
}

\author{
Zecchino, Antonio; Rezkalla, Michel M.N.; Marinelli, Mattia
}

Published in:

2016 Proceedings of the 51st International Universities Power Engineering Conference

Link to article, DOI:

10.1109/UPEC.2016.8114063

Publication date:

2016

Document Version

Peer reviewed version

Link back to DTU Orbit

Citation (APA):

Zecchino, A., Rezkalla, M. M. N., \& Marinelli, M. (2016). Grid Frequency Support by Single-Phase Electric Vehicles: Fast Primary Control Enhanced by a Stabilizer Algorithm. In 2016 Proceedings of the 51st International Universities Power Engineering Conference IEEE. https://doi.org/10.1109/UPEC.2016.8114063

\section{General rights}

Copyright and moral rights for the publications made accessible in the public portal are retained by the authors and/or other copyright owners and it is a condition of accessing publications that users recognise and abide by the legal requirements associated with these rights.

- Users may download and print one copy of any publication from the public portal for the purpose of private study or research.

- You may not further distribute the material or use it for any profit-making activity or commercial gain

- You may freely distribute the URL identifying the publication in the public portal 


\title{
Grid Frequency Support by Single-Phase Electric Vehicles: Fast Primary Control Enhanced by a Stabilizer Algorithm
}

\author{
Antonio Zecchino, Michel Rezkalla, Mattia Marinelli \\ Center for Electric Power and Energy, Department of Electrical Engineering, DTU - Technical University of Denmark \\ Contact person: Antonio Zecchino (antozec@elektro.dtu.dk)
}

\begin{abstract}
Electric vehicles are growing in popularity as a zero emission and efficient mode of transport against traditional internal combustion engine-based vehicles. Considerable as flexible distributed energy storage systems, by adjusting the battery charging process they can potentially provide different ancillary services for supporting the power grid. This paper presents modeling and analysis of the benefits of primary frequency regulation by electric vehicles in a microgrid. An innovative control logic algorithm is introduced, with the purpose of curtailing the number of current set-point variations that the battery needs to perform during the regulation process. It is shown that, compared to traditional droop-control approaches, the proposed solution assures same effects in terms of frequency containment, by employing a considerably lower number of variations of battery current set-point. The modeled low voltage microgrid is built to reproduce a real configuration of the experimental facility SYSLAB-PowerLabDK. Root-meansquare simulation studies have been carried out in DIgSILENT PowerFactory environment for the validation of the controller.
\end{abstract}

Index Terms-- Distributed Energy Resources, Electric Vehicle, Fast Primary Control, Frequency Support.

\section{INTRODUCTION}

Traditionally, frequency stability is assured relying on ancillary services provided by conventional large power plants, which nowadays are being replaced by renewable energy sources. This leads to the need of providing such services relying more and more on small aggregated units mostly connected to LV grids. Therefore, aiming at deferring grid reinforcement investments, system-wide ancillary services from distributed energy resources (DERs) need to be provided without violating distribution grids constraints.

Electric vehicles (EVs) can represent a reliable source of such services, since they can boast technical properties suitable for offering flexibility to the grid operators. In fact, they can be considered as distributed energy storage systems with large potential for network regulation [1], [2], and are almost continuously plugged into a LV charging post [3]. Furthermore, they are capable of adjusting the battery charging process according to pre-defined algorithms [4]-[8].

In [9]-[11] it is shown that EVs with or without vehicle-togrid (V2G) capability can be effective in primary frequency regulation, both in isolated microgrids and larger systems. However, an ideal EV response to the control signals was assumed, in terms of response time and power, while communication and control latencies were neglected. These simplifications may greatly impact the results.

To fill this gap, in the here-presented paper both the EVs and the control/communication procedure are modelled considering appropriate response times and latencies for all the operational steps. EV response characteristics are based on the experimental finding described in [12]. Modeling and analysis of the effects of primary frequency regulation by single-phase EVs without V2G capability in an islanded LV microgrid are presented. Specifically, the work proposes an original controller to reduce the number of EV current setpoint variations. The controller prevents undesired unstable situations due to frequency oscillations caused by the 1-Amp granularity for the setting of the charging current, foreseen by IEC61851 [13] and J1772 [14] standards.

For the characterization of the proposed controller, different droop functions are set, and, with the purpose of reproducing the real different behaviors that EVs may have, different response times are considered. In this way, situations of load unbalance among the three phases are introduced. These considerations allowed a further validation of the proposed controller. The implemented control algorithm complies with contemporary standards for limiting the EV charging rate. This means that it can be applied with all currently available EVs complying with [13] and [14]. For the validation of the controller, root-mean-square (RMS) simulations are carried out in DIgSILENT PowerFactory software environment. Both load events to destabilize the system frequency, and a realistic wind generation profile to create continuous frequency deviations are considered. To allow a future practical experimental validation study, the modelled microgrid, is built to reproduce a real configuration of the experimental facility SYSLAB-PowerLabDK.

The paper is structured as follows. Section II presents the modelled microgrid. Primary frequency regulation control by EVs is reported in Section III, together with a detailed description of the proposed innovative controller. Section IV presents the simulation studies: three scenarios are defined, and results are presented and discussed. Conclusions are reported in Section V. 


\section{MICROGRID LAYOUT}

The study has been carried out by means of RMS simulation activities in DIgSILENT PowerFactory software environment. The modelled grid is a reproduction of an islanded configuration of the experimental LV grid SYSLABPowerLabDK. SYSLAB-PowerLabDK is a research laboratory facility for development and test of control and communication technology for active and distributed power systems, located at the DTU Risø campus.

In order to allow a future practical experimental validation study, the modelled microgrid, was built considering real available power system components. Specifically, the following units were considered for the proposed simulation studies:

- 3 controllable EVs, each equipped with single-phase 16 A $(230 \mathrm{~V})$ charger and $24 \mathrm{kWh}$ Lithium-ion battery. The chargers allow only unidirectional power flows, i.e., not any V2G capability is utilized. The charging current can, however, be modulated between 6 and 16 A with granularity of $1 \mathrm{~A}$ [13], [14].

- A 60 kVA diesel synchronous generator, with active power provision up to $48 \mathrm{~kW}$. Since designed for operating in microgrid contexts, the inertia of the unit is rather high $(2 \mathrm{H}$ $=50 \mathrm{~s}$ ). To allow the analysis of primary frequency regulation by $\mathrm{EVs}$, the automatic frequency control of the governor of the diesel generator has been disabled.

- A $45 \mathrm{~kW}$ (up to $15 \mathrm{~kW}$ per phase) resistive load unit with active power independently settable on each phase.

- A $10 \mathrm{~kW}$ Aircon wind turbine (nominal wind speed: 11 $\mathrm{m} / \mathrm{s}$ ) with full converter and active stall power control.

As deducible from the highlights in the single line diagram representation of the whole mentioned experimental facility in Fig. 1, a $725 \mathrm{~m}$ Aluminum cable line is utilized to connect the two buses which the components are connected to (ACResistance at $20{ }^{\circ} \mathrm{C}$ and Reactance are respectively 0.313 and $0.077 \mathrm{Ohm} / \mathrm{km})$. Both the synchronous and the wind generators are connected to the same bus, while the resistive load and the EVs are placed on the other terminal of the line.

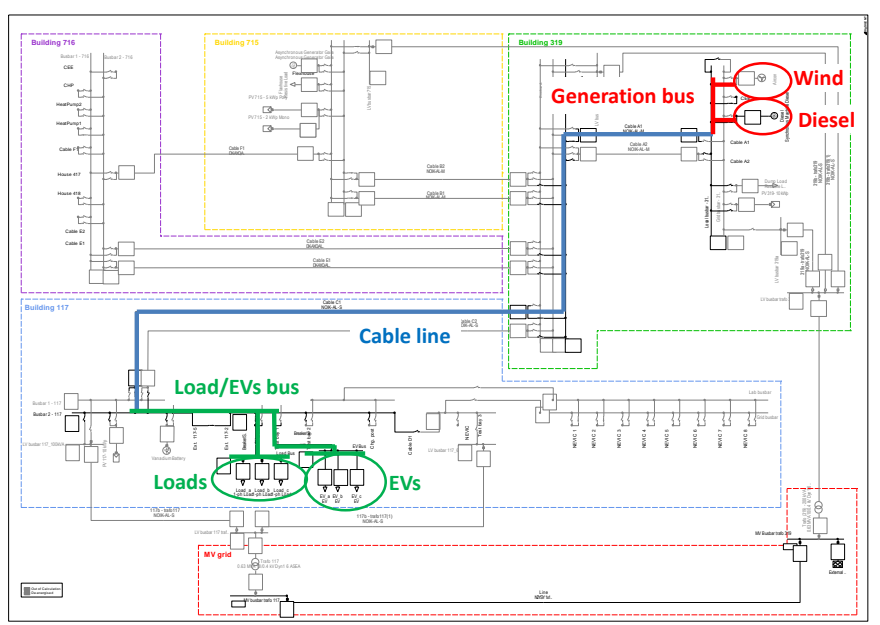

Fig. 1. Single line diagram representation of the whole SYSLABPowerLabDK experimental LV grid. Highlighted are the components utilized to compose the microgrid.

\section{CONTROLLERS}

This Section introduces a first possible approach for primary frequency regulation by EVs. Secondly, it describes the problem of undesired current oscillations. Finally, it presents the innovative logic algorithm to enhance the performances of the controller by preventing the oscillations.

\section{A. FPC controller}

By exploiting the high ramping times and precision that EVs can assure for primary frequency regulation [12], the regulation service here presented will be called Fast Primary Control (FPC).

Commonly, primary frequency control is provided by droop controllers, which modulate the synchronous machines' generation according to the power rating. The droop constant $k_{\text {droop }}$ represents how much the machine is sensible to frequency changes, and quantifies its contribution to primary frequency/power regulation. The contribution in terms of active power variation $\Delta P[\mathrm{~kW}]$ referred to its nominal power $P_{n}[\mathrm{~kW}]$ is correlated to the frequency variation $\Delta f[\mathrm{~Hz}]$ referred to the nominal value $f_{n}(50 \mathrm{~Hz})$ by $k_{\text {droop }}$, as in (1).

$$
\Delta f / f_{n}=k_{\text {droop }} \cdot \Delta P / P_{n}
$$

In our application, the regulation is provided by EVs (loads), by modulating their power consumption. According to [13] and [14], the charging process is modulated by setting the charging current. Therefore, Equation (1) can be rewritten as in (2), where, for a defined droop, $\Delta I$ [A] is the current variation that the $\mathrm{EV}$ will assure in case of a certain $\Delta f$.

$$
\Delta f / f_{n}=k_{\text {droop }} \cdot \Delta I / I_{n}
$$

It is clear that, in order to define the droop value, the nominal current $I_{n}$ - the correspondent of $P_{n}$ in (1) - needs to be set. So, as the technical requirements delimit EV's charging current between 6 and $16 \mathrm{~A}$, this available range of regulating current of $10 \mathrm{~A}$ has been assumed as the EV's $I_{n}$.

For this study, three different proportional f-I droops have been considered: $2 \%$ (frequency limits of $49.5-50.5 \mathrm{~Hz}$ ), $4 \%$ $(49-51 \mathrm{~Hz})$, and $6 \%(48.5-51.5 \mathrm{~Hz})$. If the frequency exceeds the limits, then the current limit value $(6$ or $16 \mathrm{~A})$ is set. The three droops are showed in Fig. 2 by the dashed lines.

In order to comply with the aforementioned [13] and [14] standards, the calculated current values need to be rounded. This results in step functions, showed by the solid lines in Fig. 2. To assure room to increase and decrease the charging level equally ( $\pm 5 \mathrm{~A})$, the EVs' initial current set-point is $11 \mathrm{~A}$, the central point.

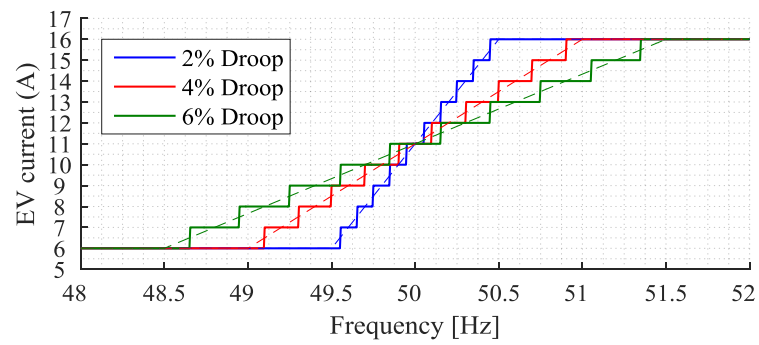

Fig. 2. $2 \%, 4 \%$ and $6 \%$ f-I droops: ideal and step functions. 
Technically, EVs are largely capable of satisfying the requirements in terms of activation time for participating in the Danish market for primary frequency reserve in both the synchronous regions DK1 and DK2 [12]. In fact, DK1 requires the supply of the first half of the activated reserve within $15 \mathrm{~s}$ and the rest within $30 \mathrm{~s}$, while DK2 requires the activation of the full reserve within $150 \mathrm{~s}$. In practice, the participation in the Danish market is hindered by the minimum bid of $0.3 \mathrm{MW}$. This would correspond to a minimum number of EVs of about 260, considering a $\pm 5 \mathrm{~A}$ flexibility per vehicle. Therefore, it is clear that an aggregator is needed to manage such a large number of units.

In this context, with the aim of reproducing a realistic scenario in which more EVs are managed by one single aggregator, the charging process of the three EVs is here managed by the same controller, which relies on a unique frequency measurement device. So, the EVs' inverters receive the same current set-point signal. It is clear that, in an ideal case of perfectly equal response time and inverter performance, the cars would charge exactly in the same way.

The controller's block diagram is shown in Fig 3-a. Basically, it is composed by three main blocks: the frequency measurement device, the control algorithm and the EV model. As explained, the control algorithm in Fig. 3-b receives the frequency measurement and provides the EV current set-point according to a particular f-I droop. To comply with the standards, the 'Round' block rounds the calculated current value. To represent the digital time delay due to measurement and communication, a time delay block is inserted inside the control algorithm block $\left(T_{m c}=0.5 \mathrm{~s}\right)$. The rounded current signal is sent to the EV model, which is composed by:

- A time constant block to imitate the EV battery dynamics.

- A time delay block to represent the delay due to internal EV communication and activation of the inverter $\left(T_{E V}=1.5 \mathrm{~s}\right)$.

- A block that converts the current to a power signal, as for RMS simulations in PowerFactory loads need power inputs. - A load block, i.e., the EV unit in the modelled grid.
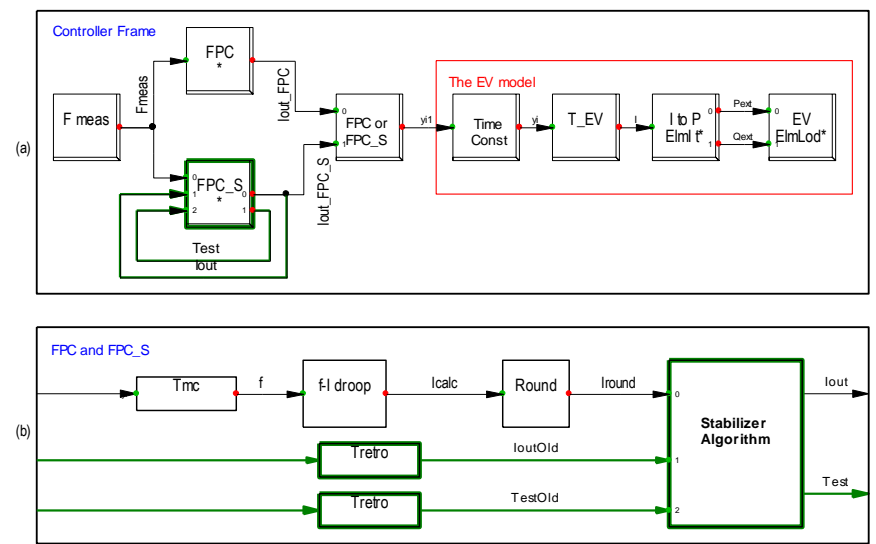

Fig. 3. Controller block diagram. The highlights show the parts added for FPC_S. (a) shows the measurement block, the control algorithm (FPC or FPC_S) and the EV model. (b) shows the control algorithm block diagram.

\section{B. Current oscillations}

In occasion of recent frequency regulation experimental and simulation activities in a microgrid using FPC by EVs, the authors have experienced some frequency oscillations [12]. The oscillations are due mainly to the technical requirement of 1-Amp granularity for the setting of the changing current. In fact, the rounding provided by the 'Round' block can cause 1-Amp oscillations, especially in presence of steep droops, low-inertia grid, large response times and high share of EVs power employed as reserve. The reason is the calculated current, which, in case it falls near the exact middle of two consecutive set-points, will be continuously rounded up and down.

For example, if the calculated current is $7.51 \mathrm{~A}$, then the set-point will be $8 \mathrm{~A}$. The same set-point signal is sent to an aggregated number of EVs. The difference between the 7.51 $\mathrm{A}$ and the $8 \mathrm{~A}$ in all the EVs would cause a significant change in the power flow in terms of total absorbed active power. This will affect the frequency, resulting in a new calculated current of $7.49 \mathrm{~A}$, rounded down to $7 \mathrm{~A}$. This process will turn in a loop that determines the 1-Amp oscillations.

\section{Addition of a Stabilizer Algorithm: FPC_S controller}

With the aim to avoid the mentioned 1-Amp current oscillations, an innovative controller called FPC_S is implemented. The proposed controller prevents 1-Amp current oscillations, while allows larger and highly lessprobable 2-Amp or higher ones. This will reduce the overall probability of current oscillations.

To build the FPC_S controller, in addition to the presented FPC controller, the 'Stabilizer Algorithm' block is inserted. It, as the retroaction arrows, is highlighted in the block diagrams in Fig. 3. Basically, the Stabilizer Algorithm freezes the current set-point if a 1-Amp oscillation is detected. The Stabilizer Algorithm's flow-chart is presented in Fig 4. The controller calculates the current set-point (Iout) based on an algorithm which evaluates two conditions: the current setpoint and an internal parameter (Test). The first condition is obtained by comparing the new calculated set-point (Iround) with the one from the previous time step (IoutOld). The second condition is evaluated through a consideration of a memory status (TestOld), which is the Test from the previous time step. Test indicates whether or not, and how, the current set-point is going to change compared to the value of the

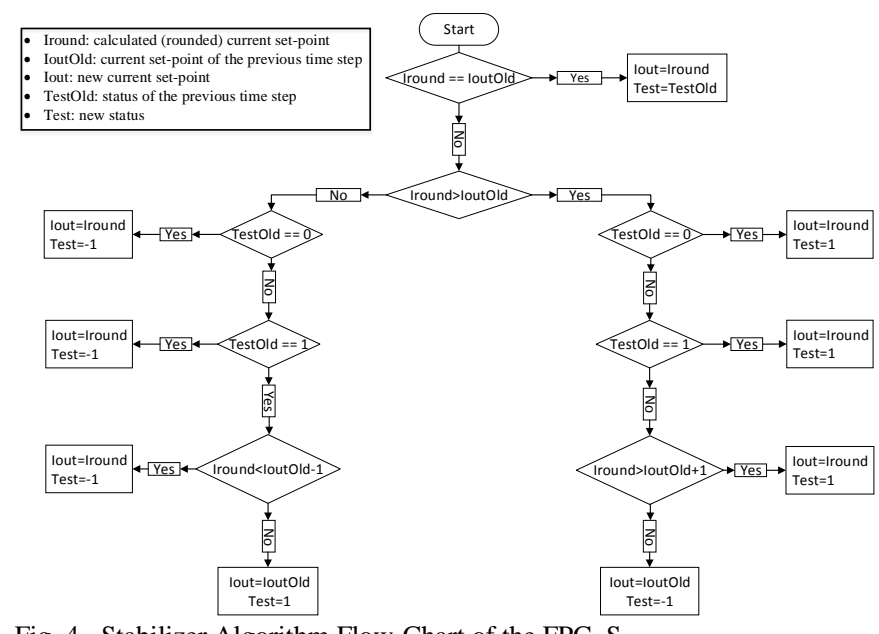

Fig. 4. Stabilizer Algorithm Flow-Chart of the FPC_S. 
previous time step. It will take the values of $-1,0$ or 1 : the -1 indicates that in the previous time step the current set-point has been reduced, the 1 that it has been increased, while 0 is utilized for the initialization of the controller.

Since the aim of the controller is to avoid 1-Amp oscillations, the algorithm prevents 1-Amp steps from one time step to the next one under certain conditions. To do this, the algorithm compares Iround with IoutOld taking into account the value of TestOld. For instance, in case Iround is greater than IoutOld by 1-A difference, and TestOld is -1 then Iout will be kept as IoutOld. On the other hand, Iout will be changed only when the difference is at least $2 \mathrm{~A}$.

To give a practical example, if Iround is 9 A, IoutOld is 8 A and TestOld is -1 then the controller prevents the current change. In fact Iout will take the same value of Ioutold and Test will be kept as TestOld. In case Iround will increase to $10 \mathrm{~A}$, then the current change will be allowed: Iout will be 10 A and Test will be 1 .

\section{SIMULATIONS: SCENARIOS’ DEFINITION AND RESULTS}

In order to evaluate the controller's effectiveness under different operating conditions, three scenarios have been considered and straightaway introduced. The purpose of the first scenario is to provide a general evaluation of the innovative FPC_S controller in case of contingencies taking place during stationary situations. On the other hand, the other two scenarios are characterized by continuous fluctuations of generation from the wind turbine, which now has been considered connected. This made it possible to evaluate the effectiveness of the controllers in a more realistic case, i.e., when continuous actions of the controllers are needed to follow continuous frequency deviations.

For Scenario \#1, in the initial situation, the diesel power generation amounts to $19.5 \mathrm{~kW}$, which corresponds to $12 \mathrm{~kW}$ of the resistive load (i.e., $4 \mathrm{~kW}$ per phase) plus $7.5 \mathrm{~kW}$ of the three EVs (i.e., $2.5 \mathrm{~kW}$ each, which corresponds to the mentioned initial condition of 11 A). For Scenarios \#2 and $\# 3$, both load and EVs are kept as in \#1, while, instead, the wind turbine is now considered connected.

\section{A. Scenario \#1}

The first scenario aims at evaluating the FPC_S controller, by monitoring the frequency trends in case of balanced load events. The events have been used to destabilize the microgrid frequency, whose deviations will be contained by the FPC_S. The simulations have been carried out for a time slot of 20 minutes, during which, with intervals of 5 minutes, the events took place, as in Table I. The events' size amounts to $\pm 3 \mathrm{~kW}$, which corresponds to $\pm 15.4 \%$ of the total generated power and to $\pm 5 \%$ of the rated power of the diesel generator.

TABLE I

LOAD EVENTS FOR DESTABILIZING THE FREQUENCY

\begin{tabular}{|c|c|}
\hline Time & Load event \\
\hline $10 \mathrm{~s}$ & $+3 \mathrm{~kW}$ \\
\hline $310 \mathrm{~s}$ & $-3 \mathrm{~kW}$ \\
\hline $610 \mathrm{~s}$ & $-3 \mathrm{~kW}$ \\
\hline $910 \mathrm{~s}$ & $+3 \mathrm{~kW}$ \\
\hline
\end{tabular}

Comparisons of results with and without the Stabilizer Algorithm have been repeated for each one of the three droops presented in Section III-A, namely $2 \%, 4 \%$ and $6 \%$. In this way, the effectiveness of the proposed controllers in case of different frequency limitations and slopes of the proportional controller has been tested.

Results from Fig. 5 show that, in case of $2 \%$ droop, the first and third load events led to undesired frequency fluctuations, due to the mentioned 1-Amp oscillations. It is possible to notice that they are substantially reduced by the FPC_S controller, which drastically reduces the number of switches from one set-point to the other (Fig. 6-a and Table II). An enlargement of the frequency deviations appears since it imposes to wait until the frequency change is big enough to make the set-point change by $2 \mathrm{~A}$ at the time. Similar effects are noticeable after the first event in case of $6 \%$ droop, with the difference that now not any larger fluctuation is caused.

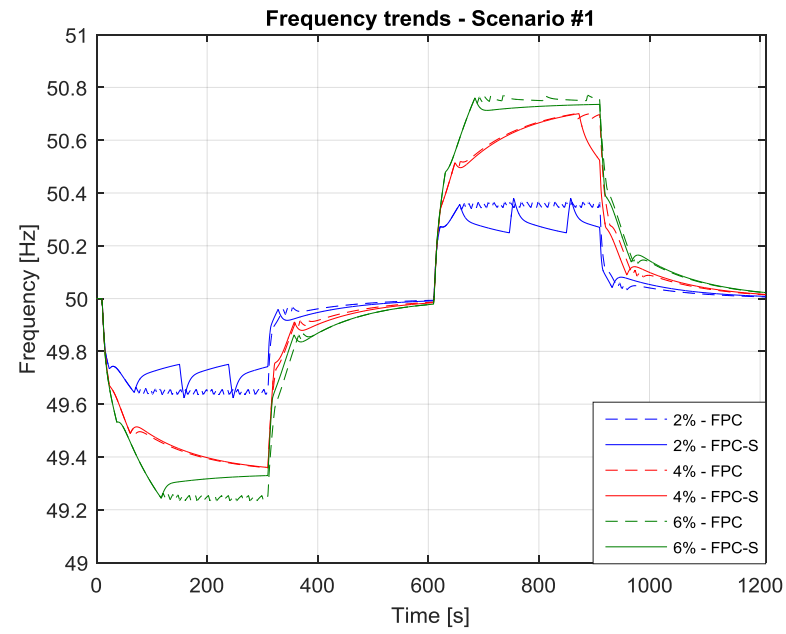

Fig. 5. Frequency trends employing FPC and FPC_S in Scenario \#1.
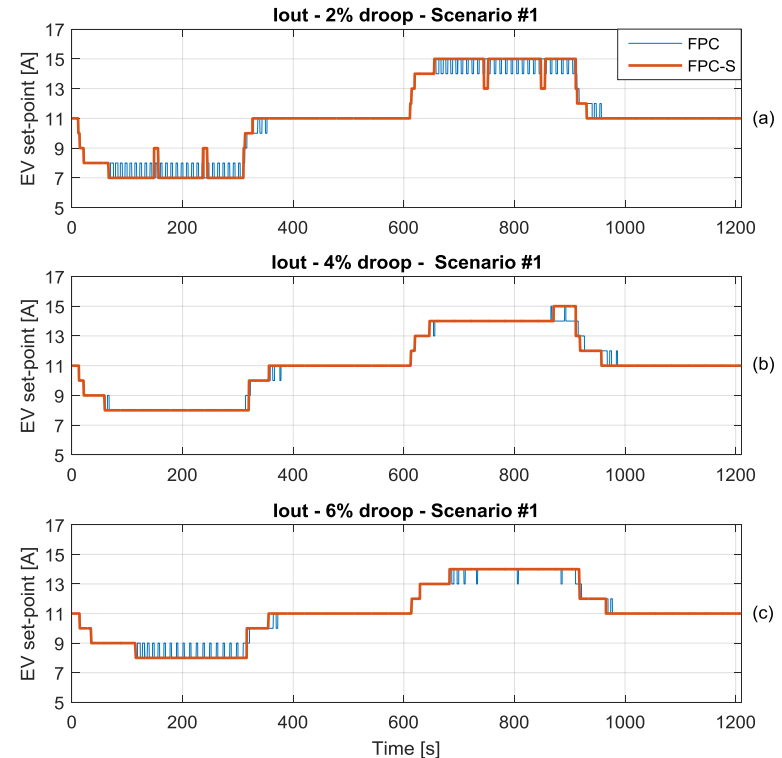

Fig. 6. EV current set-point signals employing FPC and FPC_S in Scenario $\# 1$. For $2 \%$ droop (a), for $4 \%$ droop (b), for $6 \%$ droop (c). 
As general result for the three cases, it can be concluded that the primary frequency regulation effects are basically the same and potential oscillation conditions are avoided, with an absolute minor number of EV current set-point switching, as deducible from Fig. 6 and Table II.

TABLE II

RESULTS' OVERVIEW FOR SCENARIO \#1

\begin{tabular}{|c|c|c|c|c|c|c|c|c|}
\hline \multirow{2}{*}{ Droop } & \multicolumn{4}{|c|}{ FPC } & \multicolumn{4}{|c|}{ FPC_S } \\
\cline { 2 - 9 } & $\begin{array}{c}\text { Nr. } \\
\text { switchings }\end{array}$ & $\mathrm{f}_{\max }$ & $\mathrm{f}_{\min }$ & $\mathrm{f}_{\text {mean }}$ & $\begin{array}{c}\text { Nr. } \\
\text { switchings }\end{array}$ & $\mathrm{f}_{\max }$ & $\mathrm{f}_{\min }$ & $\mathrm{f}_{\text {mean }}$ \\
\hline $2 \%$ & 128 & 50.37 & 49.64 & 50.00 & 22 & 50.38 & 49.63 & 50.00 \\
\hline $4 \%$ & 28 & 50.70 & 49.36 & 50.02 & 12 & 50.70 & 49.36 & 50.01 \\
\hline $6 \%$ & 62 & 50.77 & 49.23 & 50.01 & 10 & 50.76 & 49.24 & 50.02 \\
\hline
\end{tabular}

\section{B. Scenario \#2}

Scenario \#2 considers a 30-minute wind production profile, in terms of active and reactive power, reported in Fig. 7. This allows an evaluation of the controllers in case of a realistic case, i.e., when continuous actions of the controllers are needed to follow continuous frequency variations.

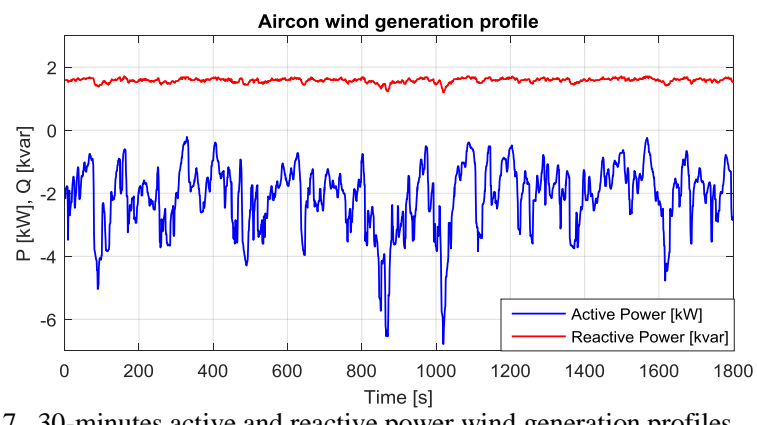

Fig. 7. 30-minutes active and reactive power wind generation profiles.

Fig. 8 shows that, as it was for Scenario \#1, for all the considered droops the overall primary frequency containment benefits are not so influenced by the use of the additional Stabilizer Algorithm. A confirmation of this is provided by the numerical results in Table III, in terms of maximum, minimum and mean frequency values. Table III reports also frequency information in case of totally uncontrolled situation, the case presented by the black line in Fig. 11.

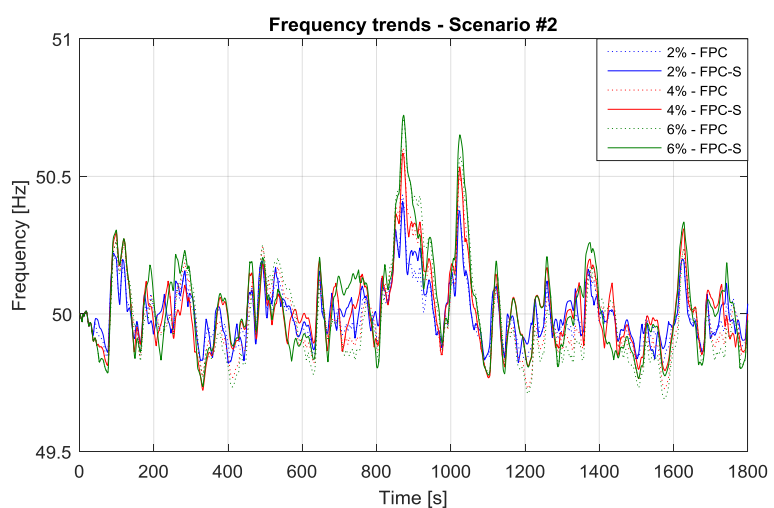

Fig. 8. Frequency trends employing FPC and FPC_S in Scenario \#2.

On the other hand, the FPC_S controller provides absolute benefits in terms of EV current set-point adjustments number, as deducible from Fig. 9. In fact, as reported in Table III, for the $2 \%, 4 \%$ and $6 \%$ droops, the switch operations have been
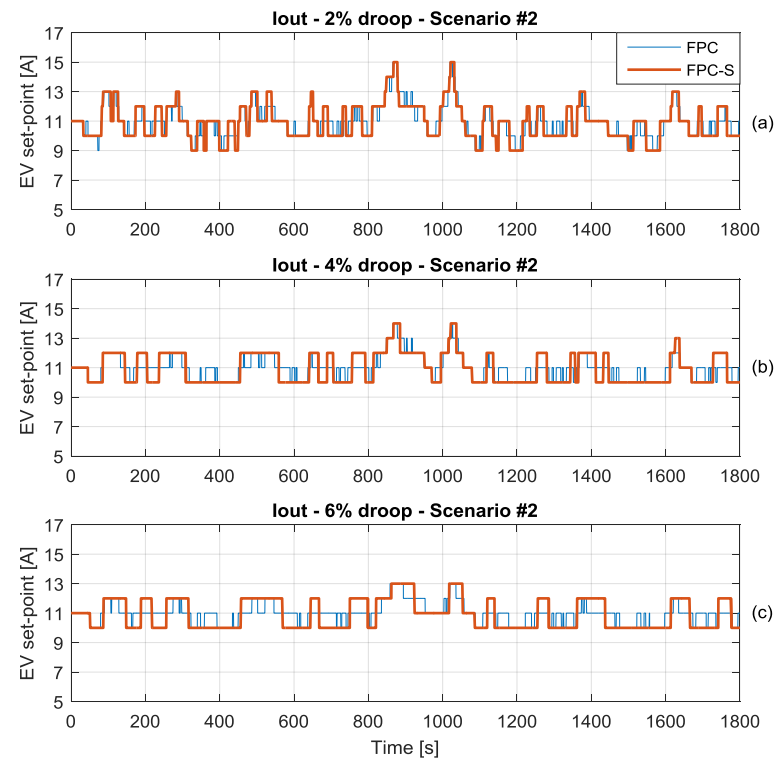

Fig. 9. EV current set-point signals employing FPC and FPC_S in Scenario \#2. For $2 \%$ droop (a), for $4 \%$ droop (b), for $6 \%$ droop (c).

reduced by $48 \%$ (from 166 to 87 ), $59 \%$ (from 106 to 43 ) and $67 \%$ (from 88 to 29 ), respectively.

This result is very significant, especially if considered in a future scenario with EVs providing frequency regulation for the whole duration of the charging process. In fact, the FPC_S solution, allows significantly less degradation of the EV battery, assuring same performances in terms of frequency regulation.

Also the phase-neutral voltages at the EVs' connection point are monitored. It has been verified that the FPC_S controller does not influence them significantly.

TABLE III

RESULTS' OVERVIEW FOR SCENARIO \#2

\begin{tabular}{|c|c|c|c|c|c|c|c|c|}
\hline \multirow{2}{*}{ Droop } & \multicolumn{4}{|c|}{ FPC } & \multicolumn{4}{c|}{ FPC_S } \\
\cline { 2 - 10 } & $\begin{array}{c}\text { Nr. } \\
\text { switchings }\end{array}$ & $\mathrm{f}_{\max }$ & $\mathrm{f}_{\min }$ & $\mathrm{f}_{\text {mean }}$ & $\begin{array}{c}\text { Nr. } \\
\text { switchings }\end{array}$ & $\mathrm{f}_{\max }$ & $\mathrm{f}_{\text {min }}$ & $\mathrm{f}_{\text {mean }}$ \\
\hline $2 \%$ & 166 & 50.43 & 49.82 & 49.99 & 87 & 50.41 & 49.82 & 50.00 \\
\hline $4 \%$ & 106 & 50.60 & 49.73 & 49.99 & 43 & 50.58 & 49.72 & 50.02 \\
\hline $6 \%$ & 88 & 50.71 & 49.69 & 49.99 & 29 & 50.72 & 49.74 & 50.03 \\
\hline No Contr. & - & 51.11 & 49.34 & 49.99 & - & - & - & - \\
\hline
\end{tabular}

\section{Scenario\#3}

The main purpose of Scenario \#3 is analyzing a situation characterized by different response times of the three EVs. In this way it is possible to reproduce the real different behaviors that EVs may have, although simultaneously receiving the same signal. As EVs are connected to different phases, controllers are tested in case of random unbalanced conditions, caused by the unsynchronized set-point variations.

Scenario \#3 considers the same 30-minute wind production profile utilized for Scenario \#2. However, only the 4\% droop is considered. With the purpose of obtaining different EV response times, with reference to the block scheme representation of the EV model (in Fig. 3-a), it has been decided to modify the digital delay-time $T_{E V}$. For each time- 
step of the RMS simulation, $T_{E V}$ has been randomly changed for each EV, with values of $1.5 \mathrm{~s}, 2 \mathrm{~s}, 2.5 \mathrm{~s}$ or $3 \mathrm{~s}$.

Fig. 10 reports a zoom-in capture of the switching events of the three EVs. It is possible to notice how the three EV setpoints are changed in a non-synchronous way. The trends for the whole 30-minutes simulation is not reported, since it appears exactly as in Fig. 9-b (orange line).

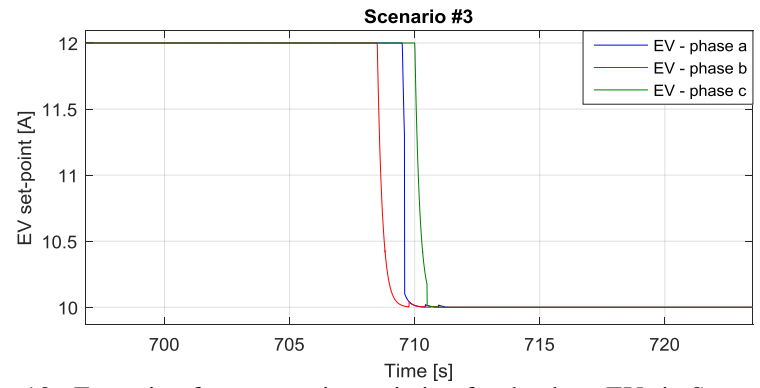

Fig. 10. Zoom-in of one set-point variation for the three EVs in Scenario \#3.

As deducible from Fig. 11, the microgrid frequency is not subject to any kind of oscillations. This leads to the conclusion that, although the frequency is regulated by units with different response times that introduce unbalance conditions to the system, the proposed FPC_S controller does not cause any kind of system instability. Results also show that the Voltage Unbalance Factor ( $\mathrm{VUF}_{\%}$, defined in [15]) is contained below $0.18 \%$. It would increase up to $0.3 \%$ in case the diesel generator would have only half of its apparent power or one tenth of its inertia. In any case, the unbalance introduced by the EVs in the microgrid is rather small, considering that the maximum acceptable limit is $2 \%$.

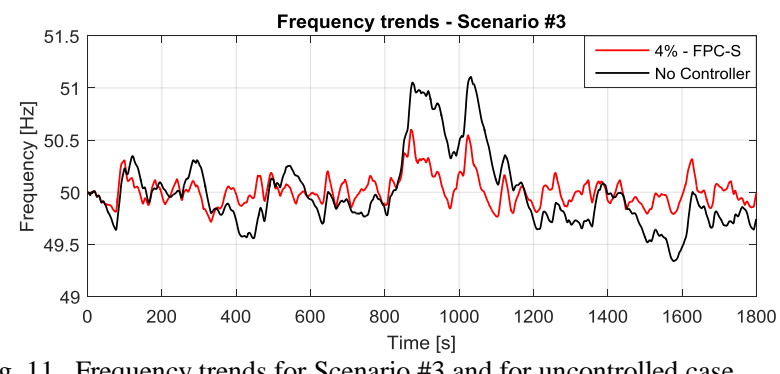

Fig. 11. Frequency trends for Scenario \#3 and for uncontrolled case.

\section{CONCLUSIONS AND FUTURE WORKS}

This work presented modeling and analysis of frequency regulation provided by single-phase $\mathrm{EV}$ s connected to an islanded LV microgrid. By exploiting the high ramping times and precision that EVs can assure, the analyzed grid service was named Fast Primary Frequency Control (FPC).

The paper proposed an original solution to reduce the number of EV current set-point adjustment actions, which in a microgrid might become extremely high in case of standard droop-based primary frequency regulators. Specifically, the implemented logic prevented the undesired 1-Amp oscillations that the authors had experienced in occasion of previous frequency regulation experimental and simulation activities in a microgrid using FPC by EVs. Therefore, the paper presented a practical solution to the problem that appeared due to the 1-Amp granularity foreseen by the IEC 61851 and SAE J1772 technical standards.

Results showed that the addition of a Stabilizer Algorithm to the controller (now called FPC_S) certainly provided benefits in terms of EV current set-point switchings number, assuring same performances in terms of primary frequency regulation. The FPC_S controller has been further validated: it assured system stability in case of unbalances induced by the unsynchronized responses of the 3 single-phase EVs.

As future works, the innovative controller will be implemented in a real EV charging station at the experimental facility SYSLAB-PowerLabDK. The FPC_S controller will be validated in the same microgrid that has been utilized for the here-presented simulation studies.

\section{REFERENCES}

[1] K. Knezović, M. Marinelli, P. Codani, and Y. Perez, "Distribution Grid Services and Flexibility Provision by Electric Vehicles: a Review of Options," Proceedings of the 50th International Universities Power Engineering Conference (UPEC) IEEE. Staffordshire, England, pp. 1$6,2015$.

[2] K. Clement-Nyns, E. Haesen, and J. Driesen, "The impact of vehicleto-grid on the distribution grid," Electric Power Systems Research, vol. 81, no. 1, pp. 185-192, 2011.

[3] N. S. Pearre, W. Kempton, R. L. Guensler, and V. V Elango, "Electric vehicles: How much range is required for a day 's driving?," Transportation Research Part C, vol. 19, no. 6, pp. 1171-1184, 2011.

[4] M. Esmaili and M. Rajabi, "Optimal charging of plug-in electric vehicles observing power grid constraints," IET Generation, Transmission \& Distribution, vol. 8, no. 4, pp. 583-590, 2014.

[5] C. Gouveia, C. L. Moreira, J. Abel, P. Lopes, and D. Varajão, "Microgrid Service Restoration," IEEE Industrial Electronics Magazine, vol. 7, no. 4, pp. 26-41, 2013.

[6] J. Hu, S. Member, S. You, M. Lind, J. Østergaard, and S. Member, "Coordinated Charging of Electric Vehicles for Congestion Prevention in the Distribution Grid," IEEE Transactions on Smart Grid, vol. 5, no. 2, pp. 703-711, 2014

[7] K. Knezović, M. Marinelli, R. J. Møller, P. B. Andersen, C. Træholt, and F. Sossan, "Analysis of Voltage Support by Electric Vehicles and Photovoltaic in a Real Danish Low Voltage Network," Proceedings of the 49th International Universities Power Engineering Conference (UPEC) IEEE. Cluj-Napoca, Romania, pp. 1-6, 2014.

[8] A. S. Masoum, S. Deilami, P. S. Moses, M. A. S. Masoum, and A. Abu-Siada, "Smart load management of plug-in electric vehicles in distribution and residential networks with charging stations for peak shaving and loss minimisation considering voltage regulation," IET Generation, Transmission \& Distribution, vol. 5, no. 8, pp. 877-888, 2011.

[9] P. M. R. Almeida, F. J. Soares, and J. A. P. Lopes, "Electric vehicles contribution for frequency control with inertial emulation," Electric Power Systems Research, vol. 127, pp. 141-150, 2015.

[10] S. Izadkhast, P. Garcia-Gonzalez, and P. Frias, "An Aggregate Model of Plug-In Electric Vehicles for Primary Frequency Control," IEEE Transactions on Power Systems, vol. 30, no. 3, pp. 1475-1482, 2015.

[11] J. Meng, Y. Mu, H. Jia, J. Wu, X. Yu, and B. Qu, "Dynamic frequency response from electric vehicles considering travelling behavior in the Great Britain power system," Applied Energy, vol. 162, pp. 966-979, 2016.

[12] M. Marinelli, S. Martinenas, K. Knezović, and P. B. Andersen, "Validating a centralized approach to primary frequency control with series-produced electric vehicles," Journal of Energy Storage, vol. 7, pp. $63-73,2016$

[13] IEC 61851-1:2010, "Electric vehicle conductive charging system Part 1: General requirements." 2010.

[14] SAE J1772:2010, "Electric vehicle and plug in hybrid electric vehicle conductive charge coupler." 2010.

[15] P. Pillay and M. Manyage, "Definitions of voltage unbalance," IEEE Power Engineering Review, vol. 22, no. 11, pp. 49-50, 2002. 